\title{
Analytical strategy for determination of chloramphenicol in different biological matrices by liquid chromatography - mass spectrometry
}

\author{
Tomasz Śniegocki, Małgorzata Gbylik-Sikorska, Andrzej Posyniak \\ Department of Pharmacology and Toxicology \\ National Veterinary Research Institute, 24-100 Pulawy, Poland \\ sniego@piwet.pulawy.pl
}

Received: June 6, 2017 Accepted: August 31, 2017

\begin{abstract}
Introduction: The main problem in determination of chloramphenicol in food of animal origin is a large number of matrices. The main target of this study was to create a method for determination and confirmation of chloramphenicol in products and food of animal origin. Material and Methods: Each $5 \mathrm{~g}$ matrix sample was mixed with $5 \mathrm{~mL}$ of water and $10 \mathrm{~mL}$ of acetonitrile/ethyl acetate, homogenised, and centrifuged. The organic layer was evaporated and redissolved in $6 \mathrm{~mL}$ of $4 \% \mathrm{NaCl}$. The extract was cleaned up by SPE technique. Chloramphenicol was analysed by LC-MS/MS in electrospray mode. Results: The procedure was validated according to the Commission Decision No. 2002/657/EC. The apparent recoveries were in the range of $92.1 \%$ to $107.1 \%$ with a repeatability less than $11.0 \%(4.4 \%-11.0 \%)$ and within-laboratory reproducibility below $13.6 \%(4.7 \%-13.6 \%)$. Conclusion: The method was successfully validated and proved to be efficient, precise, and useful for quantification of chloramphenicol in more than 20 different matrices.
\end{abstract}

Keywords: food of animal origin, chloramphenicol, residues, analytical method.

\section{Introduction}

Chloramphenicol (CAP) is an effective broadspectrum antibiotic that has been used since the 1950s in all animal species. The toxic effects of CAP for humans led to the limitation of its use in veterinary practice. The general adverse side effect in humans is dose-related suppression of the bone marrow, resulting in erythropenia, leukopenia, or thrombocytopenia. The antibiotic is not authorised for use in food-producing animals in the European Union (2). Data from the Rapid Alert System for Food and Feed (RASFF) indicate that since 2004, incidents of contamination of various matrices with CAP have been detected, and 488 notification events for CAP contamination have been reported, among which 442 regarded food and 46 feed (6). The notifications are related to a wide range of food products, particularly the crustaceans and products thereof, honey, meat and meat products, milk and dairy products, fish and aquaculture products, water, and feed. The CAP presence in food of animal origin is complex and depends on many factors. This article presents a method for determination of CAP in more than 20 different biological matrices in which CAP could be present and should be determined.

\section{Material and Methods}

Materials. Acetonitrile was from Merck (Germany). Chloramphenicol- $\mathrm{D}_{5} \quad\left(\mathrm{CAP}-\mathrm{D}_{5}\right)$ and $\beta$ glucuronidase type HP-2 from Helix pomatia were obtained from Sigma-Aldrich (USA). Acetic acid, ammonium acetate, methanol, isopropanol, ethyl acetate, and octadecyl C18 cartridges $(500 \mathrm{mg}, 6 \mathrm{~mL}$ ) were from J.T. Baker (the Netherlands). Sodium chloride $(\mathrm{NaCl})$ was purchased from P.O.Ch. (Poland). Kinetex C8 column $(75 \mathrm{~mm} \times 2.1 \mathrm{~mm} \times 2.6 \mu \mathrm{m})$ and $\mathrm{C} 8$ precolumn $(4 \mathrm{~mm} \times 2 \mathrm{~mm} \times 4 \mu \mathrm{m})$ were purchased from Phenomenex (USA). All reagents were of analytical grade or higher.

Individual stock standard solution of CAP and internal standard (CAP-D $\left.{ }_{5}\right)$ solutions $\left(1 \mathrm{mg} \mathrm{mL}^{-1}\right)$ were prepared in methanol and stored in the dark at $<-18^{\circ} \mathrm{C}$, no longer than one year. The working standard and internal standard solutions at the level of $0.01 \mu \mathrm{g} \mathrm{mL}^{-1}$ 
were prepared in methanol and stored in the dark at $<6^{\circ} \mathrm{C}$, no longer than six months.

LC-MS/MS. The LC-MS/MS system consisted of an Sciex API 5500 Qtrap mass spectrometer (SCIEX, Canada) equipped with an electrospray ionisation (ESI) unit and Agilent Series 1200 HPLC system (Agilent Technologies, Germany). The Analyst 1.6.2 software controlled the LC-MS/MS system and processed the data. The mass spectrometer was operated in the negative ESI mode with a capillary voltage of $4.5 \mathrm{kV}$. The multiplier was set at $2,100 \mathrm{~V}$. The temperature of desolvation was set at $400^{\circ} \mathrm{C}$, gas 1 (air) - 35 psi; gas 2 (air) - 35 psi; curtain gas $\left(\mathrm{N}_{2}\right)-40$ psi; nebuliser gas $\left(\mathrm{N}_{2}\right)-40$ psi; collision gas $\left(\mathrm{N}_{2}\right)-$ medium. The chromatography was performed on a Kinetex C8 column (75 mm $\times 2.1 \mathrm{~mm}$ i.d., particle size $2.6 \mu \mathrm{m})$, connected to a $\mathrm{C} 8$ precolumn $(4 \mathrm{~mm} \times 2 \mathrm{~mm}$ i.d., particle size $4 \mu \mathrm{m})$. The mobile phase for LC analysis consisted of two solutions: A (0.5\% isopropanol in $0.1 \%$ acetic acid) and $\mathrm{B}$ (methanol). The LC flow programme was: 0-2.5 min $85 \%$ A, 2.5-3.0 $\min 55 \%$ A, $4.2 \min 1085 \%$ A. The column was maintained at $40^{\circ} \mathrm{C}$ at a flow rate of the mobile phase which was $0.4 \mathrm{~mL} / \mathrm{min}$ and injection volume was $10 \mu \mathrm{L}$. The ions monitored by multiple reactions monitoring $(\mathrm{MRM})$ were $321 \rightarrow 152$ then $321 \rightarrow 194$. The collision energy (CE) for CAP was $-22 \mathrm{eV}$ for the first transition and $-18 \mathrm{eV}$ for the second one, while the declustering potential (DP) was $-20 \mathrm{eV}$.

Sample preparation. For the method optimisation and validation process, samples of commercially available pig and poultry feeds were collected. Urine, plasma, and water were obtained from a livestock farm from different species like pigs and cattle. The rest of matrices were collected from the local supermarkets. Samples were checked to be free of the CAP residues. The samples were stored at $\angle-18^{\circ} \mathrm{C}$ until the experiment.

Extraction 1: butter, eggs, fat, sour cream, milk, curd cheese, feed, sausage, and headcheese. A $5 \mathrm{~g}$ portion of a sample with $30 \mu \mathrm{L}$ (CAP-D5) of internal standard were mixed with $5 \mathrm{~mL}$ of water, $1 \mathrm{~g}$ of $\mathrm{NaCl}$, and $10 \mathrm{~mL}$ of acetonitrile, homogenised, and centrifuged at $2,930 \times$ ref for $10 \mathrm{~min}$ at a temperature of about $6^{\circ} \mathrm{C}$. The top layer of extract was taken and evaporated until dry using a gentle nitrogen stream at $45^{\circ} \mathrm{C}$, redissolved in $6 \mathrm{~mL}$ of $4 \% \mathrm{NaCl}$, and after that $3 \mathrm{~mL}$ of hexane was added and shaken carefully. The cleanup with hexane was repeated once again. The solution was cleaned up by solid-phase extraction technique.

Extraction 2: water, whey, honey, mead, royal jelly, and aquaculture products. A $5 \mathrm{~g}$ portion of a sample with $30 \mu \mathrm{L}$ (CAP-D5) of internal standard was mixed with $5 \mathrm{~mL}$ of water and $10 \mathrm{~mL}$ of ethyl acetate, homogenised, and centrifuged at $2,930 \times \mathrm{rcf}$ for $10 \mathrm{~min}$ at a temperature of about $6^{\circ} \mathrm{C}$. The top layer of the extract was taken and evaporated until dry using a gentle nitrogen stream at $45^{\circ} \mathrm{C}$, redissolved in $6 \mathrm{~mL}$ of $4 \%$ $\mathrm{NaCl}$, and after that $3 \mathrm{~mL}$ of hexane was added and shaken carefully. The cleanup with hexane was repeated once again. The solution was cleaned up by solid-phase extraction technique.

Extraction 3: liver, urine, plasma, muscle, and kidney. To the $5 \mathrm{~g}$ portion of sample with $30 \mu \mathrm{L}$ (CAPD5) of internal standard, $3 \mathrm{~mL}$ of $0.05 \mathrm{M}$ acetate buffer, $\mathrm{pH} 5.2$, and $50 \mu \mathrm{L}$ of $\beta$-glucuronidase was added and the mixture was homogenised for approx. $1 \mathrm{~min}$. The samples were hydrolysed for $1 \mathrm{~h}$ at $50^{\circ} \mathrm{C}$. After hydrolysis, $10 \mathrm{~mL}$ of ethyl acetate was added and the samples were homogenised and then centrifuged at $2,930 \times \operatorname{rcf}$ for $10 \mathrm{~min}$ at a temperature of about $6^{\circ} \mathrm{C}$. The top layer of extract was taken and evaporated until dry using a gentle nitrogen stream at $45^{\circ} \mathrm{C}$, redissolved in $6 \mathrm{~mL}$ of $4 \% \mathrm{NaCl}$, and after that, $3 \mathrm{~mL}$ of hexane was added and shaken carefully. The cleanup with hexane was repeated once again. The solution was cleaned up by solid-phase extraction technique.

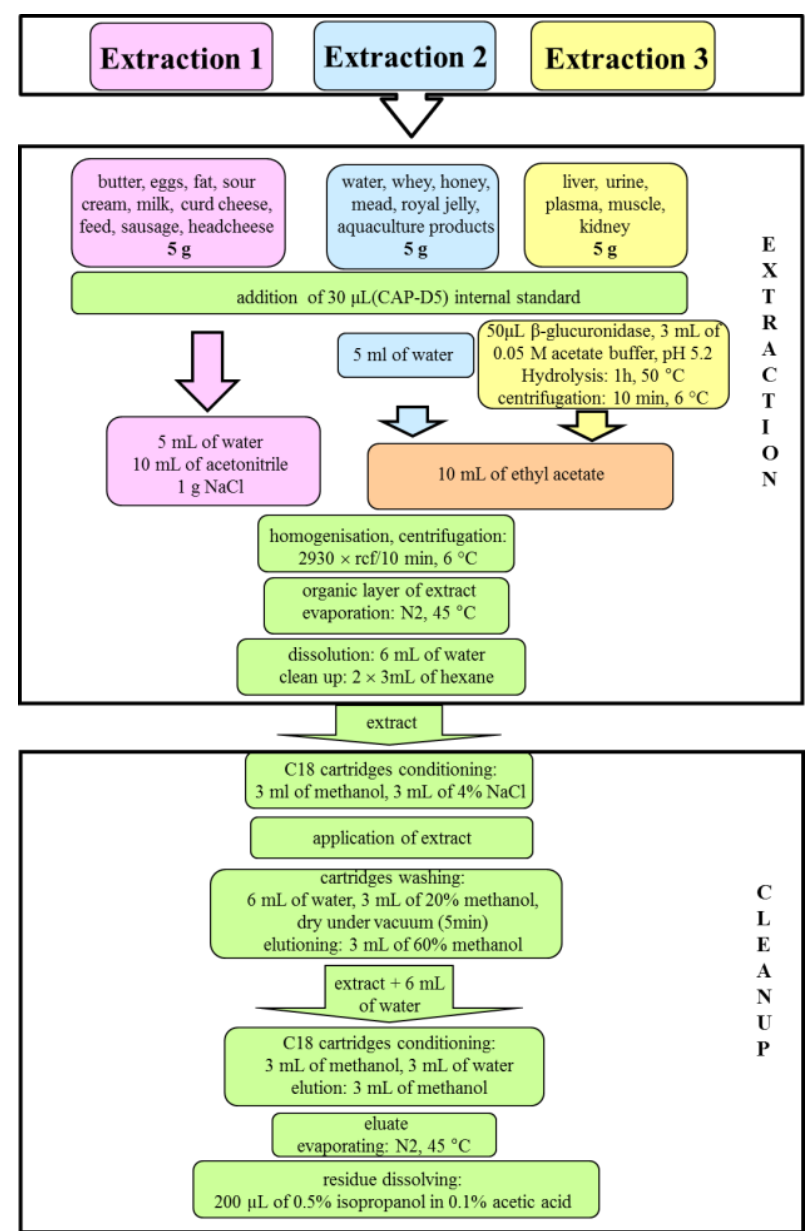

Fig. 1. Multi-matrix sample preparation for chloramphenicol determination

Solid-phase extraction conditions. SPE octadecyl columns were pre-prepared with $3 \mathrm{~mL}$ of methanol and $3 \mathrm{~mL}$ of $4 \% \mathrm{NaCl}$. When the extract was applied on the column, the column was washed with $6 \mathrm{~mL}$ of water, after that with $3 \mathrm{~mL}$ of $20 \%$ methanol, and dried under reduced pressure for $5 \mathrm{~min}$. CAP was eluted with $3 \mathrm{~mL}$ of $60 \%$ methanol. After that the eluate was diluted with $5 \mathrm{~mL}$ of water and the solution was mixed and passed 


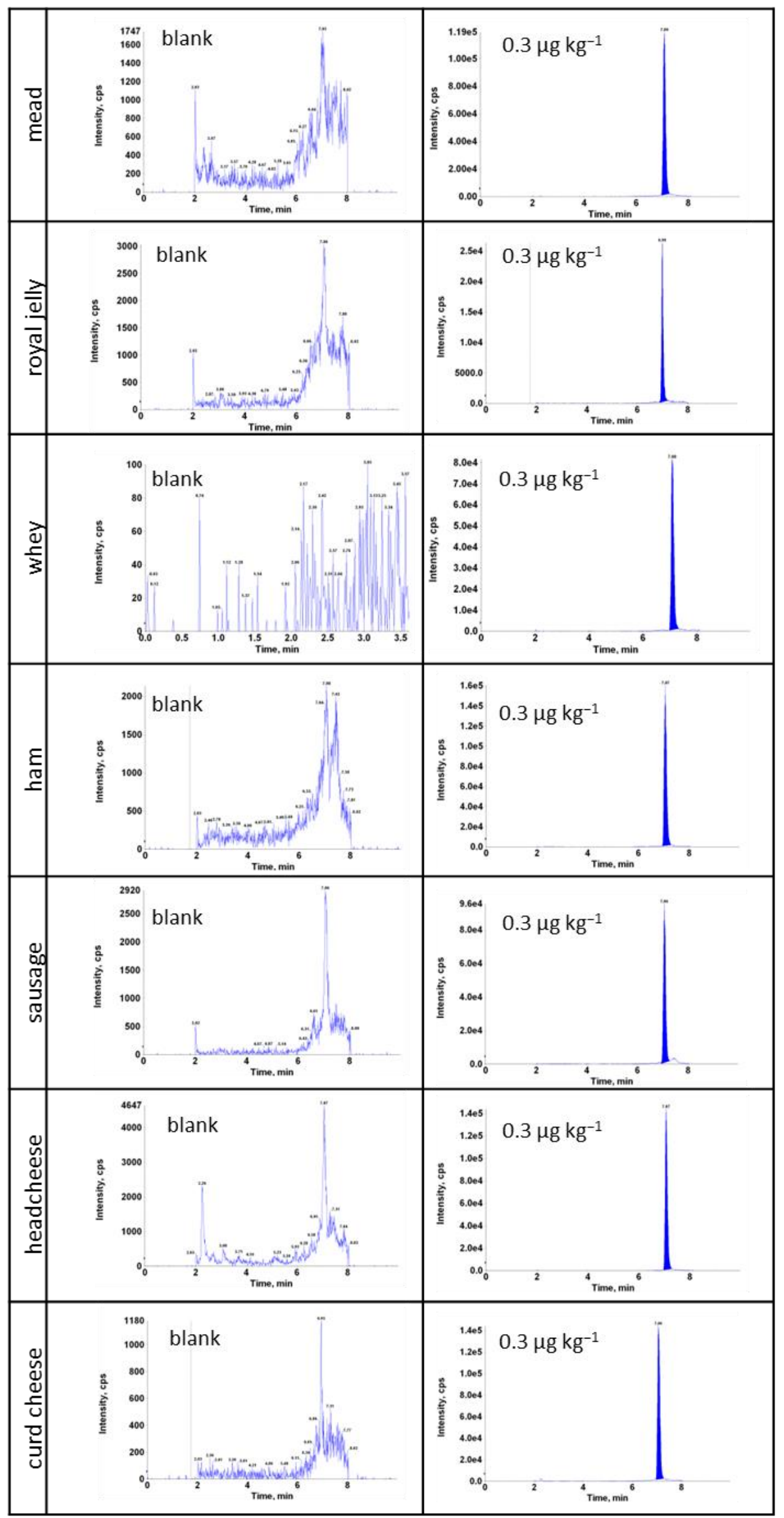

Fig. 2. Chromatograms of different matrices, blank and CAP spiked sample $\left(0.3 \mu \mathrm{g} \mathrm{kg}^{-1}\right)$ 
through new SPE octadecyl columns pre-prepared with $3 \mathrm{~mL}$ of methanol and $3 \mathrm{~mL}$ of water, and finally eluted with $3 \mathrm{~mL}$ of methanol. The eluate was evaporated under a gentle nitrogen stream to dryness at $45^{\circ} \mathrm{C}$, dissolved in $200 \mu \mathrm{L}$ of $0.5 \%$ isopropanol in $0.1 \%$ acetic acid, and analysed by LC-MS/MS. The sample preparation diagram is presented in Fig. 1. Example chromatograms are shown in Fig. 2.

\section{Results}

The procedure was validated according to the Commission Decision No. 2002/657/EC (2). The analysis of 20 blank samples for each matrix did not reveal any interference. The criteria concerning relative retention time of the analytes were corresponding to that of the calibration solution at a tolerance of $\pm 2.5 \%$. A good linearity $\left(\mathrm{R}^{2}\right)$ for all concentration levels $\left(0.1-10.0 \mu \mathrm{g} \mathrm{kg}^{-1}\right)$ was obtained in the range of $0.99-0.998$. The apparent recoveries for all concentration levels $\left(0.1-10.0 \mu \mathrm{g} \mathrm{kg}^{-1}\right)$ were in the range of $92.1 \%$ to $107.1 \%$ with a repeatability less than $11.0 \%(4.4 \%-11.0 \%)$, and within-laboratory reproducibility below $13.6 \%(4.7 \%-$ $13.6 \%)$. The limit of decision $(\mathrm{CC} \alpha)$ and detection capability $(\mathrm{CC} \beta)$ values were also determined and presented in Table 1. The individual stock solutions stored at $<-18^{\circ} \mathrm{C}$ were stable for 12 months. The stability of the stock and working solutions stored at $6^{\circ} \mathrm{C}$ was six months. The stability of extracts for each of the analysed matrices was estimated for at least two weeks at $<-18^{\circ} \mathrm{C}$. Table 1 contains the summary of the data obtained from validation process.

The expanded uncertainty was calculated at the $0.3 \mu \mathrm{g} \mathrm{kg}^{-1}$ concentration level applying a coverage factor of 2, which provides a level of confidence of approximately $95 \%$ (Table 1). The calculated ion suppression of the matrix effects for CAP in all matrices did not exceed $15 \%$ and indicated that it was not a problem of this method (Table 1).

\section{Discussion}

LC-MS/MS conditions. To achieve the maximum selectivity, the mass spectrometry parameters including ionisation mode, desolvation gas temperature, source temperature, desolvation gas, capillary voltage, cone voltage, and the collision energy were optimised by direct flow infusion. One precursor ion and two product ions were selected for CAP to compare signal-to-noise ratio $(\mathrm{S} / \mathrm{N})$ and to meet the required criteria (2). Separation of CAP is generally performed by LC using reversed-phase $\mathrm{C} 18$ or $\mathrm{C} 8$ silica columns with a mixture of water-acetonitrile, water buffer, or methanol as mobile phase $(3,5,8)$.

Due to the large quantity of difficult matrices, we did not decide to use our previously described mobile phase for determination of CAP, where CAP had a short retention time (13), but we decided to create a new method with very good separation, symmetric peak shape, and longer retention time for CAP but with a similar analysis time. In order to find the best composition of a mobile phase, a few different mobile phases were tested (acetic acid: methanol or acetonitrile; $5 \mathrm{mM}$ ammonium formate: methanol or acetonitrile, $0.5 \%$ isopropanol: methanol or acetonitrile; $0.5 \%$ isopropanol in $0.1 \%$ acetic acid: methanol or acetonitrile; $5.0 \%$ isopropanol in $0.1 \%$ acetic acid: $5 \%$ isopropanol in ethanol). The best separation (symmetric peak shape and minimal matrix effect) and longer retention time of the CAP was estimated with the use of $0.5 \%$ isopropanol in $0.1 \%$ acetic acid: methanol.

Table 1. Validation report for chloramphenico

\begin{tabular}{|c|c|c|c|c|c|c|c|}
\hline Matrix & $\begin{array}{l}\text { Repeatability, } \\
\left(\operatorname{RSD}_{\mathrm{r}}, \%\right)\end{array}$ & $\begin{array}{l}\text { Within-laboratory } \\
\text { reproducibility, } \\
\left(\mathrm{RSD}_{\mathrm{wR}}, \%\right)\end{array}$ & $\begin{array}{l}\mathrm{CC} \alpha \\
\left(\mu \mathrm{g} \mathrm{kg}^{-1}\right)\end{array}$ & $\begin{array}{l}\mathrm{CC} \beta \\
\left(\mu \mathrm{g} \mathrm{kg}^{-1}\right)\end{array}$ & $\begin{array}{l}\text { Apparent recovery } \\
(\%)\end{array}$ & $\begin{array}{l}\text { Matrix } \\
\text { effect }(\%)\end{array}$ & $\begin{array}{l}\text { Expanded } \\
\text { uncertainty } \\
\left(\mu \mathrm{g} \mathrm{kg}^{-1}\right)\end{array}$ \\
\hline water & $6.7 \pm 5.4$ & $7.4 \pm 6.1$ & 0.09 & 0.13 & $106.5 \pm 0.8$ & $3.0 \pm 1.0$ & $0.3 \pm 0.03$ \\
\hline feed & $9.0 \pm 4.6$ & $13.6 \pm 5.4$ & 0.12 & 0.18 & $92.1 \pm 2.8$ & $9.0 \pm 5.5$ & $0.3 \pm 0.09$ \\
\hline urine & $8.0 \pm 3.7$ & $8.7 \pm 4.5$ & 0.12 & 0.16 & $105.0 \pm 4.1$ & $6.0 \pm 2.0$ & $0.3 \pm 0.05$ \\
\hline plasma & $8.1 \pm 3.4$ & $8.7 \pm 4.2$ & 0.1 & 0.12 & $95.0 \pm 2.81$ & $6.5 \pm 2.5$ & $0.3 \pm 0.03$ \\
\hline muscle & $8.9 \pm 3.5$ & $10.4 \pm 3.6$ & 0.11 & 0.16 & $107.1 \pm 3.1$ & $5.3 \pm 2.5$ & $0.3 \pm 0.06$ \\
\hline liver & $8.6 \pm 4.2$ & $11.6 \pm 5.6$ & 0.09 & 0.12 & $94.1 \pm 4.8$ & $8.3 \pm 3.0$ & $0.3 \pm 0.07$ \\
\hline kidney & $7.5 \pm 3.3$ & $8.2 \pm 3.6$ & 0.1 & 0.12 & $96.1 \pm 4.0$ & $6.5 \pm 2.6$ & $0.3 \pm 0.05$ \\
\hline fat & $4.4 \pm 4.7$ & $4.7 \pm 4.7$ & 0.09 & 0.12 & $100.3 \pm 2.4$ & $9.0 \pm 3.5$ & $0.3 \pm 0.07$ \\
\hline eggs & $7.4 \pm 6.1$ & $10.7 \pm 6.5$ & 0.11 & 0.15 & $97.0 \pm 0.3$ & $11.0 \pm 2.5$ & $0.3 \pm 0.05$ \\
\hline milk & $6.1 \pm 3.2$ & $7.8 \pm 5.4$ & 0.11 & 0.15 & $95.0 \pm 1.9$ & $7.0 \pm 2.5$ & $0.3 \pm 0.06$ \\
\hline honey & $11.0 \pm 3.8$ & $12.7 \pm 4.7$ & 0.11 & 0.15 & $98.7 \pm 0.3$ & $10.0 \pm 3.5$ & $0.3 \pm 0.08$ \\
\hline sausage & $8.2 \pm 3.5$ & $10.0 \pm 3.6$ & 0.1 & 0.13 & $92.0 \pm 3.9$ & $8.3 \pm 3.2$ & $0.3 \pm 0.08$ \\
\hline ham & $6.1 \pm 3.2$ & $7.1 \pm 4.2$ & 0.1 & 0.12 & $94.1 \pm 2.8$ & $6.0 \pm 2.6$ & $0.3 \pm 0.05$ \\
\hline headcheese & $6.4 \pm 3.1$ & $7.6 \pm 4.0$ & 0.09 & 0.12 & $93.3 \pm 5.0$ & $8.3 \pm 3.0$ & $0.3 \pm 0.09$ \\
\hline butter & $6.1 \pm 3.2$ & $6.5 \pm 4.6$ & 0.06 & 0.08 & $94.1 \pm 3.6$ & $9 \pm 3.0$ & $0.3 \pm 0.04$ \\
\hline sour cream & $6.4 \pm 2.2$ & $6.9 \pm 2.2$ & 0.1 & 0.14 & $96.4 \pm 2.4$ & $8 \pm 2.8 \%$ & $0.3 \pm 0.04$ \\
\hline curd cheese & $6.0 \pm 1.1$ & $7.6 \pm 0.5$ & 0.07 & 0.2 & $96.3 \pm 4.2$ & $7.5 \pm 3.0 \%$ & $0.3 \pm 0.05$ \\
\hline whey & $5.1 \pm 3.8$ & $5.3 \pm 4.0$ & 0.09 & 0.12 & $102.1 \pm 3.5$ & $3.0 \pm 1.0$ & $0.3 \pm 0.04$ \\
\hline $\begin{array}{l}\text { aquaculture } \\
\text { products }\end{array}$ & $6.1 \pm 3.2$ & $7.8 \pm 5.4$ & 0.11 & 0.15 & $95.0 \pm 1.9$ & $7.0 \pm 2.5$ & $0.3 \pm 0.06$ \\
\hline royal jelly & $8.6 \pm 4.2$ & $11.6 \pm 5.6$ & 0.09 & 0.12 & $94.1 \pm 4.8$ & $9.9 \pm 3.6$ & $0.3 \pm 0.1$ \\
\hline mead & $6.7 \pm 3.2$ & $5.6 \pm 4.2$ & 0.09 & 0.11 & $97.1 \pm 3.8$ & $6.3 \pm 3.2$ & $0.3 \pm 0.05$ \\
\hline
\end{tabular}




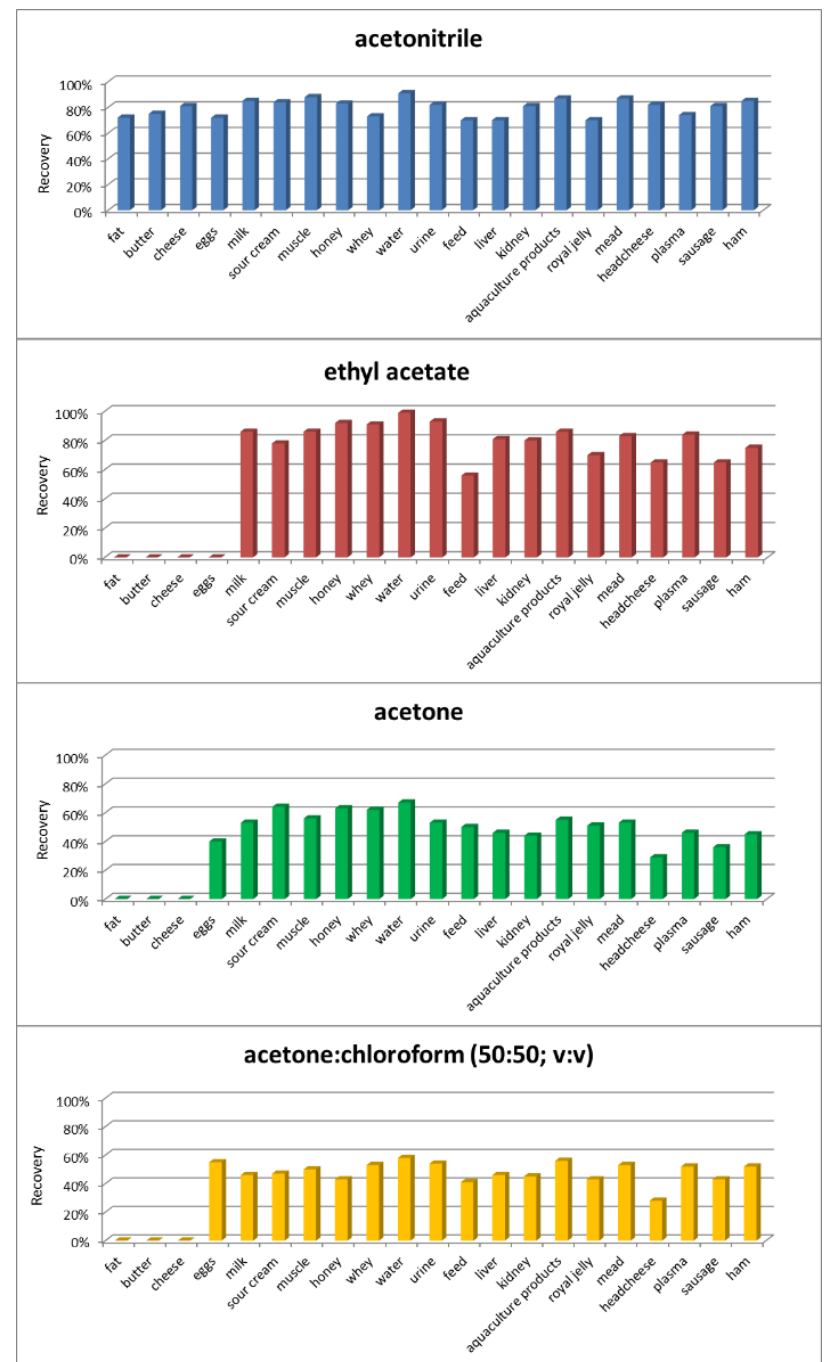

Fig. 3. Comparison of suitability of different extraction solvents for chloramphenicol

In this paper, the separation of the CAP was developed on a Kinetex C8 analytical column and a mobile phase containing $0.5 \%$ isopropanol in $0.1 \%$ acetic acid and methanol. Example of chromatograms of mead, royal jelly, whey, ham, sausage, headcheese, and curd cheese (a blank and fortified at the level $0.3 \mu \mathrm{g} \mathrm{kg}^{-1}$ ) are shown in Fig. 2.

Sample preparation. The matrices in which CAP can be determined can be divided into those which require hydrolysis - a step where CAP is present in the glucuronated form (liver, kidneys, urine, plasma) and where CAP is present as a parent drug (butter, milk, milk powder, sour cream, whey, curd cheese, water, eggs, eggs powder, aquaculture products, honey, royal jelly, mead, sausage, ham, headcheese, fat, and feed). We decided that the muscle matrix, which needs the hydrolysis step, should be added to matrices, because the latest data confirm that the recovery was higher for the muscles which were subjected to an additional step of hydrolysis (4).

In case of CAP, enzymatic hydrolysis with $\beta$-glucuronidase at $37^{\circ} \mathrm{C}$ for $16 \mathrm{~h}$, at $\mathrm{pH} \mathrm{5.2,} \mathrm{was} \mathrm{used}$ $(1,7)$. These conditions were checked and then subjected to optimisation. Two parameters were taken to optimise the conditions: time $(0.25 \mathrm{~h}, 0.5 \mathrm{~h}, 1 \mathrm{~h}, 2 \mathrm{~h}, 3 \mathrm{~h}, 4 \mathrm{~h}, 8 \mathrm{~h}$, and $16 \mathrm{~h})$ and temperature $\left(37^{\circ} \mathrm{C}, 45^{\circ} \mathrm{C}, 50^{\circ} \mathrm{C}, 55^{\circ} \mathrm{C}\right.$, and $60^{\circ} \mathrm{C}$ ). The most reproducible results, with almost $100 \%$ recovery of hydrolysis (CAP glucuronated form not detected), were already obtained after $1 \mathrm{~h}$ at a temperature of at least $50^{\circ} \mathrm{C}$. Only a few analytical methods have been described for the determination of CAP residues in multi-matrices $(7,8,10,12,14,15)$. Generally, organic solvents are used for extraction in the quantitative procedures for CAP analysis $(5,8,9)$. The extracts are then evaporated, followed by liquid-liquid or solid-phase extraction for sample cleanup and concentration. For liquid-liquid extraction steps most popular solvents are acetone, chloroform-acetone, ethyl acetate, or acetonitrile $(5,8,9,12)$. That is why in this study, the extraction was checked using these solvents. To compare the recovery, the samples were treated with ethyl acetate, acetonitrile, acetone, and chloroform: acetone (50:50), and after then centrifuged. The worst results (recovery) were with a mixture of chloroform:acetone, especially in fat, feed, butter, and cheese. The large amounts of co-extractive matrix compounds prevented evaporation to dryness. Poor results were also obtained for eggs with ethyl acetate (emulsion). Acetone and mixtures of acetonechloroform gave equally poor recovery (Fig. 3). Of course we agree with Rocha Siqueira et al. (9) that the use of phosphate extraction solution (PES) inhibits the emulsion formation in eggs, but it does not solve the problem for fat, butter, and cheese. The best extraction results for butter, curd cheese, eggs, fat, feed, sour cream, and milk were obtained using acetonitrile. At the same time, the best results for the muscles, water, whey, liver, aquaculture products, sausage, ham, headcheese, honey, royal jelly, mead, kidneys, plasma, and urine were obtained with ethyl acetate. Therefore, it was decided that acetonitrile and ethyl acetate, due to their recovery, will be used in further experiments.

Based on previous experience (13), the next step was to clean up with a double SPE C18 cartridge instead of the previously described Oasis HLB extraction cartridges (11), or Oasis MCX extraction (16). This extraction mode is less time-consuming and less laborious because it avoids $\mathrm{pH}$ adjustment and the organic solvent evaporation step in a rotary evaporator. A similar procedure was presented by Tajik et al. (15) for the determination of CAP in muscles, liver, and kidneys. Unfortunately, in our method, the use of pure methanol for the elution was not possible due to a large variety of matrices. Therefore, we tested the mixture of methanol: water in different proportions (Fig. 4). The main objective was to achieve the concentration of methanol with CAP elution with the greatest recovery, but without causing elution of residues from the matrix. The second cartridge was used for transition of CAP with the mix of water and methanol to methanol in order to speed up the evaporation process. 


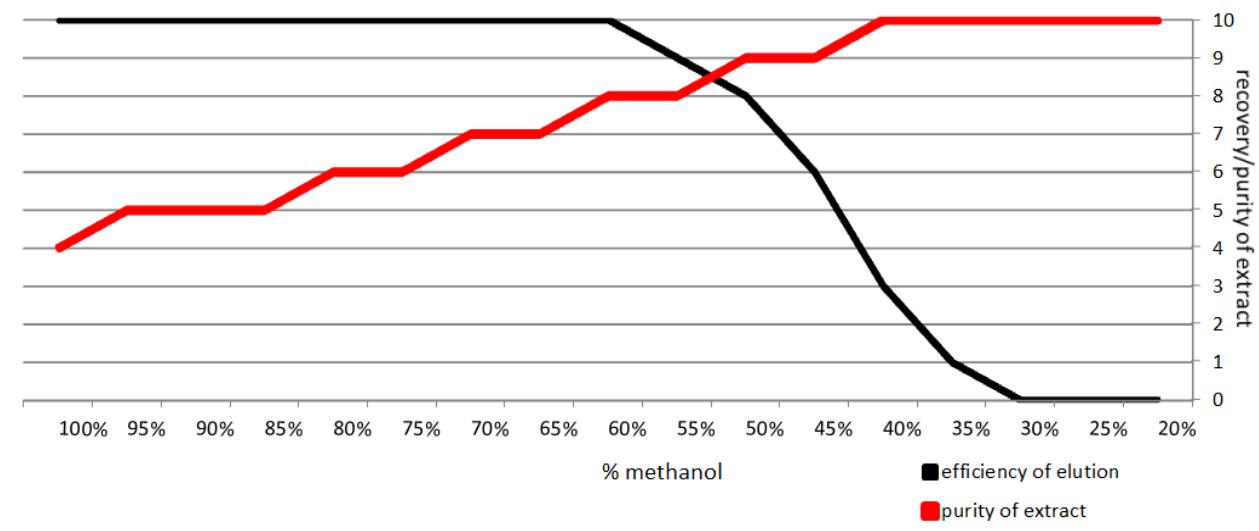

Fig. 4. Extraction efficiency for chloramphenicol in comparison to the purity of extracts

In this study, we also observed that the procedure of pre-washing extracts by hexane reduced the amount of matrix co-extractives and permitted adequate cleanup of sample extracts by SPE. The chromatographic system applied in our method exhibited enough resolution to separate the analyte peaks from matrix interference with satisfactory results.

In summary, this paper presents the complete methodology of the determination of CAP in various matrices. The validation results show that the developed method ensures a credible confirmatory data for the determination of CAP residues in all validated matrices. The accuracy and repeatability of the method were performed satisfactorily and evaluated over a dynamic range $0.10-10 \mu \mathrm{gg}^{-1}$. The $\mathrm{CC} \alpha$ and $\mathrm{CC} \beta$ values determined for CAP in various matrices were very low, indicating the high sensitivity of the method. The sample preparation can be considered straightforward and efficient, providing high sample throughput and automation capabilities. Application of the method to test samples showed no false negative or false positive results even after the analysis of a significant number of samples from different matrices, which was confirmed in many proficiency tests with $\mathrm{Z}$-scores between -2.0 and 2.0. The method can be used for the effective routine analysis of CAP in samples under the National Monitoring Plan among the EU member states and for official CAP control of products in Poland.

Conflict of Interests Statement: The authors declare that there is no conflict of interests regarding the publication of this article.

Financial Disclosure Statement: This work was supported by the Polish Ministry of Agriculture and Rural Development.

Animal Rights Statement: None required.

\section{References}

1. Berendsen B.J., Zuidema T., de Jong J., Stolker L.A., Nielen M.W.: Discrimination of eight chloramphenicol isomers by liquid chromatography tandem mass spectrometry in order to investigate the natural occurrence of chloramphenicol. Anal Chim Acta 2011, 700, 78-85.

2. Commission Decision 2002/657/EC of 12 August 2002 implementing Council Directive 96/23/EC concerning the performance of analytical methods and the interpretation of results. OJ L 221, 17.8.2002, 8-36.

3. Guy P.A., Royer D., Mottier P., Gremaud E., Perisset A., Stadler R.H.: Quantitative determination of chloramphenicol in milk powders by isotope dilution liquid chromatography coupled to tandem mass spectrometry. J Chromatogr A 2004, 1054, 365-371.

4. Kittler K., Radeck W., Polzer J.: Investigations on the influence of hydrolysis on the total amount of marker residue and consequences. Conference Material, EuroResidue VIII, in Egmond aan Zee, the Netherlands 2016. pp. 129-131.

5. Nicolich R.S., Werneck-Barroso E., Marques M.A.S.: Food safety evaluation: Detection and confirmation of chloramphenicol in milk by high performance liquid chromatography-tandem mass spectrometry. Anal Chim Acta 2006, 565, 97-102.

6. RASFF - the Rapid Alert System for Food and Feed. https://webgate.ec.europa.eu/rasff-window/portal/?event=search ResultList.

7. Rejtharová M., Rejthar L.: Determination of chloramphenicol in urine, feed water, milk, and honey samples using molecular imprinted polymer clean-up. J Chromatogr A 2009, 1216, 82468253.

8. Rezende D.R., Filho N.F., Rocha G.L. Simultaneous determination of chloramphenicol and florfenicol in liquid milk, milk powder, and bovine muscles by LC-MS/MS. Food Addit Contam A 2012, 29, 559-570.

9. Rocha Siqueira S.R., Luiz Donato J., de Nucci G., Reyes, F.G.R.: A high-throughput method for determining chloramphenicol residues in poultry, egg, shrimp, fish, swine, and bovine using LC-ESI-MS/MS. J Sep Sci 2009, 32, 4012-4019.

10. Rønning H.T., Einarsen K., Asp T.N.: Determination of chloramphenicol residues in meat, seafood, egg, honey, milk, plasma, and urine with liquid chromatography-tandem mass spectrometry, and the validation of the method based on 2002/657/EC. J Chromatogr A 2006, 1118, 226-233.

11. Shen J., Xia X., Jiang H., Li C., Li J., Li X., Ding S.: Determination of chloramphenicol, thiamphenicol, florfenicol, and florfenicol amine in poultry andporcine muscle and liver by gas chromatography-negative chemical ionization mass spectrometry. J Chromatogr B Analyt Technol Biomed Life Sci 2009, 877, 1523-1529.

12. Sniegocki T., Posyniak A., Gbylik-Sikorska M., Zmudzki J.: Determination of chloramphenicol in milk using a QuEChERSbased on liquid chromatography tandem mass spectrometry Method Anal Letters 2014, 47, 568-578.

13. Sniegocki T., Posyniak A., Zmudzki J.: Determination of chloramphenicol residues in milk by gas and liquid 
chromatography mass spectrometry methods. Bull Vet Inst Pulawy 2007, 51, 59-64.

14. Sniegocki T., Gbylik-Sikorska M., Posyniak A.: Transfer of chloramphenicol from milk to commercial dairy products experimental proof. Food Control 2015, 57, 411-418.

15. Tajik H., Malekinejad H., Razavi-Rouhani S.M., Pajouhi M.R., Mahmoudi R., Haghnazari A.: Chloramphenicol residues in chicken liver, kidney and muscle: a comparison among the antibacterial residues monitoring methods of Four Plate Test, ELISA and HPLC. Food Chem Toxicol 2010, 48, 2464-2468.

16. Vivekanandan K., Swamy M. G., Prasad S., Mukherjee R. A simple method of isolation of chloramphenicol in honey and its estimation by liquid chromatography coupled to electrospray ionization tandem mass spectrometry. Rapid Commun Mass Spectrom 2005, 19, 3025-3030. 